\begin{tabular}{|c|c|}
\hline $\begin{array}{l}\text { Ernesto Guevara y sus diarios de motocicleta. El viaje narrativo del Fúser hacia el } \\
\text { Che }\end{array}$ & Titulo \\
\hline Arreola, José - Autor/a; & Autor(es) \\
\hline $\begin{array}{l}\text { De Raíz Diversa. Revista Especializada en Estudios Latinoamericanos (Vol. } 3 \text { no. } 5 \\
\text { ene-jun 2016) }\end{array}$ & En: \\
\hline México D.F. & Lugar \\
\hline $\begin{array}{l}\text { Programa de Posgrado en Estudios Latinoamericanos, Universidad Nacional } \\
\text { Autónoma de México }\end{array}$ & Editorial/Editor \\
\hline \multirow[t]{2}{*}{2016} & Fecha \\
\hline & Colección \\
\hline $\begin{array}{l}\text { Guevara, Che; Crítica literaria; Literatura latinoamericana; Relatos de viajeros; } \\
\text { América Latina; }\end{array}$ & Temas \\
\hline Artículo & Tipo de documento \\
\hline $\begin{array}{l}\text { "http://biblioteca.clacso.edu.ar/Mexico/ppel-unam/20160630032542/6._Ernesto_Guevara_y_sus_Diarios_de_motocicleta._El_viaje_narrati } \\
\text { vo_del_Fuser_hacia_el_Che.__Jose_Arreola.pdf" }\end{array}$ & URL \\
\hline $\begin{array}{l}\text { Reconocimiento-No Comercial-Sin Derivadas CC BY-NC-ND } \\
\text { http://creativecommons.org/licenses/by-nc-nd/2.0/deed.es }\end{array}$ & Licencia \\
\hline
\end{tabular}

Segui buscando en la Red de Bibliotecas Virtuales de CLACSO http://biblioteca.clacso.edu.ar

Consejo Latinoamericano de Ciencias Sociales (CLACSO)

Conselho Latino-americano de Ciências Sociais (CLACSO)

Latin American Council of Social Sciences (CLACSO)

www.clacso.edu.ar

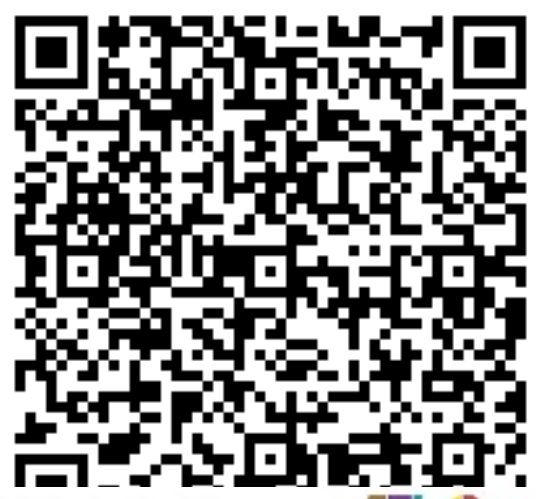

Consejo Latinoamericano de Ciencias Sociales

Conselho Latino-americano de Ciências Sociais 


\section{Ernesto Guevara y sus Diarios de motocicleta. El viaje narrativo del Fúser hacia el Che}

José ArreolA*

Resumen: Al cumplir veinticuatro años de edad, Ernesto Guevara de la Serna emprende un viaje por diferentes países de América Latina. Acompañado de Alberto Granado, su recorrido queda plasmado en unas notas de viaje que luego serán conocidas como Diarios de motocicleta. La figura de Guevara ha sido abordada desde varios puntos de vista, especialmente el que se refiere a su legado político, si bien el viaje de 1952 resulta, ciertamente, fundamental en la transformación de su mirada sobre la realidad que le rodea es asimismo muestra inaugural de un estilo de escritura. Diarios de motocicleta es el primer ejemplo de un estilo literario de retratar lo que sus ojos vieron. El viaje de Guevara, transforma su visión del mundo y como muestra de ello quedan los Diarios de motocicleta que, con chispazos de humor, certeras descripciones y un tono relajado y poético, dan fe de un trabajo literario. La vena literaria del Che es quizá la menos estudiada, de ahí la importancia de reparar en Diarios de motocicleta.

Palabras Clave: Viaje, literatura, escritura y transformación.

Abstract: At the age of twenty four, Ernesto Guevara de la Serna undertake a trip through different countries of Latin America. Accompanied by Alberto Granado, this travel get embodied in some travel notes that will be known as Motorcycle Diaries. The leading figure of Guevara has been approached from several points of view, specially the one that refer to his political legacy, although the travel of 1952 result, certainly, underlying in turning the gaze of the reality that surround him, but indeed it is also the opening for a new style of writing for us. Motorcycle Diaries is the first literary example to portray what their eyes saw. Guevara's travel, transform his world vision and as proof of this are the Motorcycle Diaries that, with sparks of humor, accurate descriptions and leisurely and poetic tone, give faith of a literary work. Maybe the literary vein of Che is the least studied, thence the importance of notice on the Mororcycle Diaries.

KEYWORDS: travel, literature, writing and underlying.

Recibido: 27 de julio de 2015. Aceptado: 18 de octubre de 2015.

E rnesto Guevara de la Serna, el Che, tuvo siempre una cercana relación con la literatura, primero como un lector voraz, luego escribiendo y

Estudiante del Doctorado del Programa de Posgrado en Estudios Latinoamericanos, <grafdar@gmail.com>. 
considerándose a sí mismo como un "poeta frustrado". Su admiración por el oficio de escribir quedó asentada en una carta dirigida a Ernesto Sábato donde confiesa que consideró el "título de escritor" como "lo más sagrado del mundo”. (Guevara, 1977: 375)

Desde pequeño, según lo han documentado sus biógrafos, era un voraz lector. En una carta fechada el 27 de noviembre de 1936, informa a su tía Beatriz "Recibí tu carta ya llegaron los libros de Salgari y los de Vigil", pasa luego a una petición "Mandame (sic) los otros cuatro libros de la colección”. Para entonces, Tete, como es llamado cariñosamente por sus familiares, tiene ocho años de edad. A un mes de cumplir los diez años, escribe nuevamente a su tía solicitando lo siguiente: "Cuando pases por la calle Santa Fe averíguame si tienen 'Los misterios de la India' de Emilio Salgari”. Ambas cartas muestran a un lector temprano que conoce lo que lee, que está desarrollando, en términos de Bourdieu, un "habitus" de lectura. Este proceso acarrea, de igual manera, la creación de una biblioteca propia.

Un elemento que merece ser destacado es el tipo de literatura que adquiere y lee: novelas de aventura. De ahí que sus autores predilectos sean Salgari, Verne, London. Las aventuras que no logra vivir físicamente, debido al asma que lo acompaña desde los dos años de edad, tendrán vida a través de la lectura. Ésta le permite desplazarse en el plano de la imaginación, rompiendo así la inmovilidad física a la que le obliga la enfermedad. Existe un trato íntimo y entrañable con lo que lee. Como anota el ensayista cubano Julio M. Llanes, "el joven lector convirtió la lectura en un permanente viaje” (Llanes, 2010: 51).

Guevara creció en un ambiente familiar culto, que apoyó a la resistencia española contra el franquismo, lleno de ajedrez, bohemia, discusiones políticas y, por supuesto, literatura. Según su padre, cuando Ernesto "llegó a los doce años, poseía una cultura correspondiente a un muchacho de 18. Su biblioteca estaba atiborrada de toda clase de libros de aventuras, de novelas de viajes" (Taibo II, 2007: 25).

Su relación con la literatura será, desde entonces, inquebrantable. Las lecturas que realiza, además de esas novelas de viaje, pasan por Quiroga, José Ingenieros, Cervantes, Neruda. Su madre "le enseña francés y lee a Baudelaire en su idioma original. Y El decameron de Bocaccio". Ya en la

\footnotetext{
1 Las cartas pueden verse en el video disponible en https://www.youtube.com/ watch?v=Fq7iYqSa-kk\&feature=youtu.be, que forma parte del proyecto de la Casa Natal de Ernesto Che Guevara, en Rosario Argentina, consultado el 28 de diciembre 2014.
} 
juventud, junto a su amigo Alberto Granado "se apasionan con Santuario de Faulkner" (Taibo II, 2007: 26).

La lectura (particularmente el gusto desarrollado por las novelas de aventura en su infancia, y su inclinación hacia la poesía durante su juventud), se convertirá en un elemento que él mismo, muchos años después, definiría como uno de sus "vicios". Existen, además, no pocas fotografías suyas, tanto en la Sierra Maestra como en las posteriores experiencias guerrilleras del Congo y Bolivia, leyendo en todo momento. Así, su ejercicio lector, su habitus desarrollado, lo conducirá a la senda de la escritura. Como ha señalado Ricardo Piglia, el Che "escribe porque lee". De esa manera, la literatura es gran parte de su mundo y el mundo se transforma en la literatura. Esa relación le despertará el deseo de convertirse en escritor con toda la carga que eso representa; es decir, asumir la creación literaria como modo de vida, fabular, inventar, hacer el mundo con las letras y relacionarse con éste a través de ellas.

\section{DIARIOS DE MOTOCICLETA, PRIMERAS IMPRESIONES}

La muestra inaugural de su sensibilidad literaria, de su capacidad escritural generadora de un efecto estético para situar al lector en un ambiente construido artísticamente, es el diario de su primer viaje por tierras latinoamericanas. Sus anotaciones del viaje darán cuerpo a Diarios de motocicleta, texto que revela a Guevara como narrador de certeras descripciones y un lenguaje poético. Esas notas del Fúser (así apodado en su juventud) son las impresiones de un recorrido que pasa por Chile, Perú, Colombia y Venezuela. La travesía inicia en los últimos días de 1951 partiendo de Córdoba, junto a su inseparable Alberto Granado. El diario nace en el viaje pero también en un segundo momento. Aunque tiene su origen en las anotaciones que levanta durante el trayecto, éstas le sirven simplemente de arranque para trabajar su relato; con ellas emprenderá un trabajo literario que resume, por un lado, su gusto y aprehensión por las novelas de viaje, por otro, se pone a prueba así mismo en el deseo de ser escritor.

Aficionado a la fotografía, Guevara capta con sus comentarios los instantes de los que no quiere olvidarse, los aprehende y los describe a detalle posteriormente. Las fotografías más hondas de su viaje son las letras que culminan en su diario. "El Che iba hacia sí mismo, entreviendo sólo, a través de anécdotas y estampas, su destino" señala Cintio Vittier (2005: 31). La observación, además de precisa, revela cómo en ese viaje Ernesto 
Guevara no sólo descubre una realidad desconocida para él hasta ese entonces, sino también la manera en que se descubre a sí mismo durante la travesía - primero en La poderosa II, luego a pie-, y en las letras que por éste nacen. En esa tríada, - viaje, letras, descubrimiento-, Guevara se transforma y esa transformación implica, indisolublemente, la configuración de un estilo particular de escribir. ${ }^{2}$

El diario inicia con una advertencia al lector. Quizá parezca un detalle nimio, sin embargo refleja, en primer término, el tono del relato en su conjunto; en segundo término, una construcción de su figura como autor que apela, explícitamente, al lector. Con ese gesto manifiesta abiertamente la intención de sus letras y muestra, asimismo, una concepción sobre el autor. Es decir, éste vale en tanto el lector pueda enojarse o coincidir con lo expuesto; en esa advertencia resulta imposible no pensar en Montaigne. Muy probablemente, Ernesto lo ha leído y al contrastar ambas advertencias se observa un parecido relevante que permitiría suponer que el joven argentino tiene como referencia al padre del ensayo. Este hecho no es menor, sobre todo si se considera su dominio del francés y sus lecturas de escritores galos. ${ }^{3}$ Cito ahora, in extenso, un fragmento de la advertencia que el Fúser elabora.

No es este el relato de hazañas impresionantes, no es tampoco meramente un "relato un poco cínico"; no quiere serlo, por lo menos. Es un trozo de dos vidas tomadas en un momento en que cursaron juntas un determinado trecho, con identidad de aspiraciones y conjunción de ensueños. Un hombre en nueve meses de su vida puede pensar en muchas cosas que van

2 Michel Foucault señaló que la literatura es "el vértice del triángulo por el que pasa la relación del lenguaje con la obra y de la obra con el lenguaje”. La observación del filósofo francés sirve de arranque para plantear a la obra literaria como obra viva, atravesada por múltiples relaciones sociales y particulares en la que el uso del lenguaje, con afán artístico, genera un efecto estético pero también configura una manera personal de escribir. Ver, De lenguaje y literatura, (traducción de Isidro Herrera), Barcelona, Instituto de Ciencias de la Educación de la Universidad Autónoma de Barcelona, Ediciones Paidós, 1996, p.64.

3 Montaigne escribe: "Este es un libro de buena fe, lector. Desde el comienzo te advertirá que con el no persigo ningún fin trascendental, sino sólo privado y familiar; tampoco me propongo con mi obra prestarte ningún servicio, ni con ella trabajo para mi gloria, que mis fuerzas no alcanzan al logro de tal designio [...]. Si mi objetivo hubiera sido buscar el favor del mundo, habría echado mano de adornos prestados; pero no, quiero sólo mostrarme en mi manera de ser sencilla, natural y ordinaria, sin estudio ni artificio, porque soy yo mismo a quien pinto. Mis defectos se reflejarán a lo vivo: mis imperfecciones y mi manera de ser ingenua, en tanto que la reverencia pública lo consienta", disponible en www. cervantesvirtual.com/obra-visor/ensayos-de-montaigne, consultado el 20 de junio del 2015. 
de la más elevada especulación filosófica al rastrero anhelo de un plato de sopa. En total correlación con el estado de vacuidad de su estómago; y si al mismo tiempo es algo aventurero, en ese lapso puede vivir momentos que tal vez interesen a otras personas y cuyo relato indiscriminado constituiría algo así como estas notas. [...]. El hombre, medida de todas las cosas, habla aquí por mi boca y relata en mi lenguaje lo que mis ojos vieron; a lo mejor sobre diez "caras" posibles sólo vi una "seca", viceversa, es probable y no hay atenuantes; mi boca narra lo que mis ojos le contaron [...]. No hay sujeto sobre quien ejercer el peso de la ley. El personaje que escribió estas notas murió al pisar de nuevo tierra Argentina el que las ordena y pule, "yo", no soy yo; por lo menos no soy el mismo yo interior. Ese vagar sin rumbo por nuestra "Mayúscula América" me ha cambiado más de lo que creí [...]. Si presento un nocturno créanlo o revienten, poco importa, que si no conocen personalmente el paisaje fotografiado por mis notas, difícilmente conocerán otra verdad que la que les cuento aquí. Los dejo ahora conmigo mismo; el que fui... (Guevara, 2005: 51-52).

No son pocos los elementos a destacar de esa advertencia al lector, pero uno de los más relevantes está anclado en la necesidad de Guevara por escribir. Esa necesidad lo lleva a relatar en primera persona. El personaje de la historia se irá mostrando en el proceso del viaje, a veces viendo "caras" otras "secas"; a veces, viviendo más holgadamente o con episodios sobre los que "no hay atenuantes". Se trata, en suma, de una construcción del relato basado en la experiencia personal del viajante aventurero que, sin embargo, al momento de escribir ya no es "el mismo yo interior". Ese "yo interior", ya transformado a la distancia de las aventuras vividas, es el que relata y pone en juego diversos elementos para entregar su narración. En una rica y extensa conversación con Mario Vargas Llosa, Gabriel García Márquez apuntó "[...] lo cierto es que el hecho de escribir obedece a una vocación apremiante, que el que tiene vocación de escribir tiene que escribir, pues sólo así logra quitarse sus dolores de la cabeza y su mala digestión" (1988: 22).

La observación del premio Nobel colombiano bien aplica al Che. Esa necesidad será un elemento invariable a lo largo de su vida, de ahí que en sus diferentes campañas guerrilleras se dé a la tarea de elaborar un diario. Diarios de motocicleta es pionero en esa labor artística de presentar literariamente la realidad que va conociendo; pero significa, de igual modo, una reconfiguración de su personalidad plasmada en lo escrito. Hay una necesidad vital de narrar, de escribir. Existe un apremio por traducir su experiencia en letra viva porque esa vida a la que se enfrentó es, a su vez, la materia de sus relatos. Lo que relata sirve de alivio a lo apremiante de las 
vivencias, las aventuras que leyó de niño se hacen, a su manera, palpables y verdaderas en el viaje y en lo que escribe. Así, lectura, viaje y escritura se convierten en elementos que transforman a Guevara.

La experiencia del viaje constituye al mismo tiempo el elemento primario de lo escrito. Es el sustrato primigenio de una forma particular de escritura, es decir, de un estilo narrativo en ciernes nacido con lo vital y vivencial de su recorrido por tierras latinoamericanas. En ese sentido, existe una doble configuración de Guevara: el del viajero que transforma su visión de la realidad latinoamericana en el recorrido y el de la escritura. $\mathrm{Su}$ forma de escribir va adquiriendo un tono y un estilo particular, lo escrito es reflejo de su nueva configuración en el mundo. Hay, ciertamente, un viaje, un desplazamiento físico por suelos y realidades desconocidas por él, pero de igual manera vive un viaje escritural. Escribir es, por esa razón, un elemento fundamental de su recorrido.

Otro aspecto destacable es su constitución como el personaje de esas notas. El Fúser es el autor de lo narrado, es quien ha pulido sus notas para ser leídas. De igual manera se transforma en el Guevara personaje protagónico de la historia, cimentando de ese modo un doble nivel de intelección en el ejercicio de escribir. El autor y el personaje unidos por lo escrito; ambos conjugándose en el diario luego de "pulir" sus primeras impresiones, es decir, luego de un trabajo con plena conciencia artística de lo relatado. Apunta que "El hombre, medida de todas las cosas, habla aquí por mi boca y relata en mi lenguaje lo que mis ojos vieron", se trata entonces de un testimonio que busca transmitir, lo más fielmente posible, lo que sus ojos fueron capaces de captar, pero lo hace a través de una labor artística. La fidelidad no la confunde con parquedad u opacidad del lenguaje, antes bien las imágenes narrativas que desarrolla le permiten, desde su perspectiva en tanto autor y personaje del relato, captar y hacer captar lo vital y más significativo de la narración.

La manera de presentarse acarrea un juego en dos niveles; a) es narrador, testigo y participante de las letras que pule y ordena; b) la narración nace, antes que con lo escrito, con las imágenes captadas por la vista que desatarán la palabra. Al iniciar la advertencia, señalando que sus letras no son el relato "de hazañas impresionantes", se despoja de cualquier atisbo de heroicidad a priori con la que se pudiera relacionar una aventura como la suya, presentándose así como un narrador honesto que no busca 
convencer de nada a nadie, sino ser fiel con lo que ha visto en el viaje $y$, especialmente, con su visión de mundo a través de lo que escribe.

Es Ernesto Guevara de la Serna el que habla, pero ocurre un desdoblamiento entre el Fúser que vive lo narrado y el Fúser que narra lo vivido. Sabe que quien "ordena y pule" las notas no es él, no el que era sino, sobre todo, el que será. Porque el "vagar sin rumbo" por la "Mayúscula América" lo ha cambiado de forma profunda. Incluso va más allá: cuando escribe que es el hombre quien habla "por su boca" no se refiere exclusivamente a su experiencia individual sino al ser humano; de tal manera su experiencia le sirve para hermanarse consigo mismo - entre su pasado, su presente y su futuro-, pero también con todos los seres humanos.

Su diario funciona, en ese sentido, como el testimonio de un personaje al que el mundo se le revela de una manera distinta a través de las aventuras y el recorrido por diversos países de Latinoamérica, pero también como lazo entre su vida, el mundo y el lector. Por eso, lo que el lector tiene ante sus ojos no es simplemente el testimonio de un viaje o las palabras del viajante, sino una experiencia que puede convertir en propia.

Dicha operación lleva la construcción literaria de un lector al que el autor se dirige directamente. Se trata de un juego complejo en el que, a la par de la escritura, surgen el autor, el personaje -o los personajes para ser más preciso, pues Alberto Granado es fundamental en la historia-, y el lector al que le propone un pacto. En su advertencia señala, quizá como un artificio para blindarse ante las críticas posibles, que "Un hombre en nueve meses de su vida puede pensar en muchas cosas que van de la más elevada especulación filosófica al rastrero anhelo de un plato de sopa", esperando no sorprender con pasajes que puedan resultar, si no desagradables, al menos subidos de tono. Apela al lector - que es, sobra decirlo, una construcción en sí misma para efectos de lo relatado-, para hacerlo más cercano a la historia, para que éste pueda verse en lo narrado, en las peripecias del viaje, en las sensaciones causadas por la aventura.

Guevara construye y despliega un relato sincero que va de la aventura a lo sublime; de la belleza a la miseria; de la ensoñación al contexto más cruel. Elaborar una advertencia al lector - como si precediera al relato, aunque en realidad sea ya parte de la narración y, en estricto sentido, el final de ésta-, con un tono en parte alejado de lo solemne, pero respetando a quien pueda llegar a leerlo, es un guiño a la experiencia humana del viaje, y lo es también a la experiencia de la lectura, ponderando la 
importancia que tiene aquel que se ocupa de leerlo. Se trata, ciertamente, de la construcción artística de lo relatado pero demuestra la importancia que para el autor tiene el lector. En suma, Guevara escribe como lector. De ahí la forma, la estructura del relato, el uso de metáforas o comparaciones; de ahí el detenerse con lujo de detalles en ciertos episodios y el lenguaje que emplea al relatar. El Fúser es el que escribe las primeras letras, pero será el incipiente Che quien las pula.

Asimismo, lo escrito habla de una búsqueda por compartir lo vivido, de sociabilizar la experiencia vital sentida por sus pasos; en otras palabras, el Fúser deseaba ser leído y su vida de lector es la que marca el modo en que sugiere se lea el relato de hazañas nada impresionantes. Diarios de motocicleta fue concebido por su autor para publicarse, para tener lectores, rebasando el plano de la intimidad.

Es posible que el diario estuviera destinado a un primer círculo de lectores: sus amigos, sus familiares. No es un diario solamente para sí mismo, por eso hay una elaboración posterior a las notas del viaje; existe, ni duda cabe, un trabajo creativo, artístico. Por tal motivo, más allá de su valor testimonial, es de resaltar la elaboración literaria para generar el efecto deseado en el lector.

El Fúser elabora el diario porque brinda al mundo el proceso de transformación que sufrió. Si el mundo se le brinda con rasgos característicos y particulares, él se otorga a éste a través de lo escrito. Mundo y escritura se transforman a la par, escribir y viajar son elementos indispensables para el joven Guevara. Además, desea y necesita compartir sus impresiones, necesita ser leído, busca sociabilizar la experiencia, tener a un lector cómplice que le "crea" o "reviente". En ese sentido, otorga a los posibles lectores una complicidad activa; busca que se enojen o que se identifiquen con él; que cuestionen su testimonio o lo hagan suyo; así, en ese abanico de posibilidades, el texto tiene la vida ya elaborada por quién vivió la experiencia del viaje, por el autor que pule las palabras y por el lector que le cree o revienta.

Cada apartado del diario inicia con un breve título para resaltar sus impresiones sobre el sitio del que escribe. El recorrido junto al inseparable Alberto Granado, luego de alistar a La poderosa II, inicia contemplando el mar, que para el Fúser "siempre fue un confidente, un amigo que absorbe todo lo que le cuentan sin revelar jamás el secreto confiado y que da el mejor de los consejos: un ruido cuyo significado cada uno interpreta como puede [...]" (Guevara, 2005: 55). 
El viajero Ernesto registra lo que el mar le significa y la manera de vivirlo a la luz de su experiencia; el mar se representa como un amigo confidente que rebasa su condición sonora y al mismo tiempo calla para dar "el mejor de los consejos". El mar es el que los lectores conocen, torrente y calma, es un significado propio, íntimo y único según pueda interpretársele ${ }^{4}$, pero con toda la carga subjetiva que el autor ha plasmado. Es el mar del lector reinterpretado por las letras de Guevara, es el mar de Guevara reinterpretado por quien lee. Para Alberto, desde la perspectiva del narrador, "es un espectáculo nuevo que le causa una turbación extraña cuyos reflejos se perciben en la mirada atenta con que sigue el desarrollo de cada una de las olas que van a morir en la playa" (Guevara, 2005: ídem).

La mirada de su amigo da razón a lo que Fúser mira. El mar se vive en los ojos de Alberto Granado y en esa mirada se significa, como en un juego de espejos, lo mirado y quien lo mira "como puede". Es de resaltar la relevancia que le otorga a la vista, como si con ella consiguiera aprehender en su totalidad al mar y permitiera adentrarse en los sentimientos de Granado al ver las olas que mueren en la playa. Éste es un recurso narrativo que aprovechará con un énfasis mayor en otros momentos del diario, pero lo relevante es cómo emplea la mirada del otro para construir la suya y así generar una narración con mucha mayor fuerza.

Hay, además, un tercer personaje del momento narrado: el perrito Come-back, "símbolo de los lazos que exigen mi retorno, sobreviviente a su propia desdicha, a dos caídas en la moto en que voló encerrado en su bolsa, a un pisotón de un caballo que lo 'descangalló' y a una diarrea pertinaz" (Guevara, 2005: 55-56).

Las líneas mencionadas retratan a un Ernesto Guevara con una mirada aguzada, poética e irreverente, que escribe tratando de sentir lo que el otro ve, con un toque de humor y amor en un solo párrafo. Come-back es un cachorrito convertido en regalo para su enamorada de entonces; es la promesa de retorno hacia ella luego de su aventura, aunque no la cumplirá porque la vida lo conduce por otro derrotero.

\footnotetext{
4 Al respecto vale la pena el análisis realizado por Luz Aurora Pimentel en Sobre la narración metafórica. La autora anota que en este tipo de narraciones, como ocurre con Lezama Lima, “[...] domina la función poética. Dicho en otras palabras, este 'relato' obliga al lector a demorarse, incluso a deleitarse, en la textura verbal y en su peculiar organización descriptivo-narrativa", ver "Narración metafórica" en Luz Aurora Pimentel, Constelaciones I. Ensayos de teoría narrativa y literatura comparada, México, Bonilla Artigas Editores-unAm (Publicritica), 2012, pp-229-236.
} 
De tal manera, el autor Guevara conjuga distintos elementos para la construcción del Fúser personaje, lo pinta en tres planos distintos en un solo acontecimiento: el que habla del mar para sí, el que ve el mar en los ojos de su acompañante y, finalmente, el enamorado (no sin una dosis de cursilería) que proyecta en el perrito de la diarrea pertinaz su juramento de volver. Existe en el Guevara narrador una intuición poética bien desarollada. Paradójicamente, él que amaba la poesía — más tarde se calificará a sí mismo como poeta frustrado-, alcanza el tono poético en sus narraciones del cual carecen los versos que escribirá.

Luego de pasar más días de lo planeados con María del Carmen Ferreyra, Chichina, la destinataria de Combe-back y a quien le dedica unos versos de Otero Silva en la despedida, los viajeros enfrentarán los primeros pasos en la austeridad. Llama la atención cómo, ante la escasez de dinero o de comida, el humor aparece casi cual bálsamo para la situación. "El pan tenía sabor de advertencia: 'Dentro de poco te costará comerme, viejo'. Y lo tragábamos con más gana, como los camellos queríamos hacer acopio de lo que viniera”. (Guevara, 2005: 62)

En los primeros apartados del diario existe un tono maravillado sobre el viaje y la posibilidad de aventura, del descubrimiento de lo ignoto, de la revelación futura en los caminos andados. "Parecía que respirábamos más libremente un aire más liviano que venía de allá, de la aventura”. Él, conviviendo con el asma, respira "libremente" en el camino como si su enfermedad se atenuara o desapareciera por completo por el hecho de viajar.

La poderosa II los lleva a cuestas descubriendo el mundo. Sufre con ellos las inclemencias del camino y las constantes reparaciones de Granado que todo lo arreglaba con "amarres de un alambre". A cualquier lugar al que arriban, la locuacidad de Alberto será capaz de convencer a los buenos samaritanos de los que obtienen ayuda. Se presentan como médicos realizando importantes investigaciones sobre epidemias y otros males que aquejan Latinoamérica. Su aspecto, sin embargo, dista mucho de la imagen que la gente puede hacerse de un galeno. El Fúser anota:

Uno de los hijos del dueño de la estancia, miraba con algo de desconfianza a estos "doctores" trajeados patibulariamente y con muestras de hambre bastante atrasada, pero se calló la boca y nos dejó comer hasta ese punto

5 A diferencia de Pasajes de la guerra revolucionaria, que narra la lucha guerrillera de Sierra Maestra, aunque mantienen las chispas de humor, aquí este elemento no es complementario sino que le da, en buena medida, cuerpo al relato. 
tan gustado por dos idealistas como nosotros, en que uno camina despacito de miedo de patearse el estómago al mover las piernas. (Guevara, 2005: 68)

El humor, la imagen cómica que presenta el narrador de sí y de su acompañante, apunta una despreocupación del mito personal que un viaje como el suyo pudiera representar; está en completa sintonía con su advertencia inicial, pero también con el modo de concebir la vida en su totalidad. No hay culto a la personalidad, más bien sorna y burla de su aspecto. Lejos de construir un discurso "heroico" del recorrido, el Fúser muestra su viaje, su descubrimiento propio, con todas sus aristas, incluso en lo risible que éste tuvo. Sin embargo, el viaje no es sólo ese andar por los suelos de la Mayúscula América en ese momento de su vida, sino que el trayecto se traduce en una sustancial revelación.

[...] casi con una fatalista conformidad en el hecho, que mi sino es viajar, que nuestro sino mejor dicho porque Alberto en eso es igual a mí, sin embargo hay momentos en que pienso con profundo anhelo en las maravillosas comarcas de nuestro sur. Quizá algún día cansado de rodar por el mundo vuelva a instalarme en esta tierra argentina y entonces, si no como morada definitiva, al menos como lugar de tránsito hacia otra concepción del mundo, visitaré nuevamente y habitaré la zona de los lagos cordilleranos (Guevara, 2005: 70).

El joven Guevara se está reconociendo, sabe de sí a través de la experiencia vivida como proyección al futuro. Viajará como destino, viajará hacia la vida. No hay momentos de su vida posterior -o incluso de su infancia con los traslados de Altagracia a Córdoba y de ésta a Buenos Aires-, que no se relacionen con la movilidad, el desplazamiento, el viaje. Conoce de sí sabiéndose en un viaje constante; ese reconocimiento ocurre asimismo en el acto creativo de escribir que significa para él un viaje a la semilla, conectándose con la naturaleza, consigo mismo:

La enorme figura de un ciervo cruzó como exhalación el arroyo y su figura plateada por la luna saliente se perdió en la espesura. Un palpetazo de 'naturaleza' nos dio en el pecho: caminábamos despacio temerosos de interrumpir la paz del santuario de lo agreste en que comulgábamos ahora (Guevara, 2005: 76, las cursivas son mías).

Cerca de Bariloche, gracias a una ponchadura de la motocicleta, necesitan acampar y nuevamente la labia de Alberto sale a flote: consiguen un galpón donde pasar la noche. Pero a causa de una confusión, debido a una historia de tigres salvajes narrada por quien les otorga posada, duermen con los 
nervios crispados. Escuchan arañazos en la puerta, el Fúser actúa según su instinto. Dispara y el cadáver de Bobby, "perro antipático y gruñón” le hace saber de su yerro. No hay nada de valentía en el relato sino la actuación de un hombre con miedo creyendo su vida en peligro. El personaje de la historia se pinta en todas sus facetas, retratándose sin solemnidad alguna. Las decepciones amorosas también son parte de sus relatos. Una carta de Chichina lo alcanza.

La dueña de Come-back, a la que antes ha jurado regresar, da por finiquitada su relación. "Me invadió una profunda desazón: es que ni siquiera eso era capaz de sentir. Empecé a temer por mí mismo e inicié una carta llorona pero no podía, era inútil insistir", pero luego se da cuenta de que "Yo creía quererla hasta ese momento en que se reveló mi falta de sentimientos, debía reconquistarla con el pensamiento. Debía luchar por ella, ella era mía, era mía, era m... me dormí”. (Guevara, 2005: 82).

La anécdota no deja de ser peculiar: va del dolor causado por la herida amorosa a la resolución graciosa, "me dormí". En adelante Chichina no aparecerá más en el plan de su vida, como si con dormir el pasado que ella representaba quedara por fin lejano e inalcanzable.

\section{NARRACIÓN Y TRANSFORMACIÓN}

Su periplo en Chile, la tierra de su amado Neruda, estará marcado por una nota del Austral de Temuco. "Dos expertos en leprología recorren Sudamérica en motocicleta"; con sarcasmo comentará: "Allí estaba la condensación de nuestra audacia. Nosotros los expertos, los hombres clave de la leprología americana [...]" (Guevara, 2005: 88). Esa nota periodística será, acompañada de la capacidad verbal de Alberto, la llave para conseguir alojamiento y comida con menos complicaciones. ${ }^{6}$ En el país andino,

6 Son varios los pasajes en los que las situaciones convocan a la risa. Por la extensión del presente texto es imposible reproducirlas en su totalidad y realizar de ellas un análisis, sin embargo el lector puede ir a los Diarios de motocicleta para ver cómo la narración del Fúser es casi hilarante en episodios de huida, de planes para sobrevivir o en cuestión de mujeres. Cito un ejemplo al respecto "[...] decidimos tirar una cana al aire en compañía de unos ocasionales amigos que nos convidaron a tomar unas copas. El vino chileno es riquísimo y yo tomaba con una velocidad extraordinaria de modo que al ir al baile del pueblo me sentía capaz de las más grandes hazañas [...] Uno de los mecánicos del taller, que era particularmente amable, me pidió que bailara con la mujer porque a él le había sentado mal 'la mezcla', y la mujer estaba calientita y palpitante y tenía vino chileno y la tomé de la mano para llevarla afuera; me siguió mansamente pero se dio cuenta de que el marido la miraba 
La poderosa II terminará su ciclo. Sin ella iniciarán una nueva etapa de sus pasos, ya no serán parte de la "aristocracia vagueril", andarán con "el mono a cuestas y con toda la mugre del camino condensada en los mamelucos".

Pero quizá lo más relevante es que sus ojos verán de un modo más profundo no ya solamente el paisaje sino a los hombres y las mujeres que lo habitan. Allí, ejerciendo de médico, ofrece una consulta a una anciana. El contacto con ella, con su enfermedad y con la imposibilidad de dar cura, lo cimbrará por completo. Gustavo Ogarrio, no sin razón, ve en el viaje de Guevara una transfiguración del personaje. Desde su perspectiva

El Che es un sujeto cuya formación política está marcada por dos actos básicos de transfiguración: el viaje, es decir, el desplazamiento geográfico que desencadena la inestabilidad y la crisis de la conciencia ante hechos como la pobreza, la desigualdad, la enfermedad y la lectura, la formación letrada que se vincula hasta fundirse con la experiencia testimonial [...] el Che Guevara lleva hasta sus últimas consecuencias su propia transfiguración, una transfiguración en la que se vinculan la política revolucionaria[...], y una formación letrada que se expresaba en ese escritor fracasado en el que se quería reconocer [...] (Ogarrio, 2009).

Esa transfiguración se ve reflejada de igual forma en su manera de narrar. Si el Fúser va aguzando la mirada, si pone mayor atención ahora al otro, al semejante, esta transformación se traduce en un cambio de tono en lo que escribe. ${ }^{7}$ La vieja chilena, "[...] daba lástima, se respiraba en su pieza ese olor acre de sudor concentrado y patas sucias, mezclado con el polvo de sus sillones, única paquetería de la casa”. El joven Guevara instala al lector en una situación complicada, lo pone junto a él en el ambiente de la miseria y la enfermedad. Escribe al respecto:

En estos casos es cuando el médico consciente de su total inferioridad frente al medio, desea un cambio de cosas, algo que suprima la injusticia

y me dijo que ella se quedaba; yo ya no estaba en situación de entender razones e iniciamos en el medio del salón una puja que dio por resultado llevarla hasta una de las puertas, cuando ya toda la gente nos miraba, en ese momento intentó tirarme una patada y, como yo seguí arrastrándola, le hice perder el equilibrio y cayó al suelo estrepitosamente. Mientras corríamos hasta el pueblo, perseguidos por un enjambre de bailarines enfurecidos, Alberto se lamentaba de todos los vinos que le hubiera hecho pagar al marido", pp.- 91-92.

7 Mijail Bajtín observó en "El problema de los géneros discursivos", que los enunciados "reflejan las condiciones específicas y el objeto de cada una de las esferas no sólo por su contenido (temático) y por su estilo verbal, o sea por la selección de recursos léxicos, fraseológicos y gramaticales de la lengua sino, ante todo, por su composición y estructuración", en Estética de la creación verbal, (traducción de Tatiana Buvnova), México, Siglo XXI, 1982, p.248 
que supone el que la pobre vieja hubiera estado sirviendo hasta hacia un mes para ganarse el sustento, hipando y penando, pero manteniendo frente a la vida una actitud erecta (2005:103).

Le conmueve el estado insalvable de la anciana, pero también su actitud de dignidad. El cambio de tono se percibe especialmente en lo preponderante de la reflexión al escribir sobre esta situación. No es meramente el retrato de lo vivido sino lo que existe antes de éste lo que le preocupa y le duele.

Allí, en estos últimos momentos de gente cuyo horizonte más lejano fue siempre el día de mañana, es donde se capta la profunda tragedia que encierra la vida del proletariado de todo el mundo; hay en esos ojos moribundos un sumiso pedido de disculpas y también, muchas veces, un desesperado pedido de consuelo que se pierde en el vacío, como se perderá pronto su cuerpo en la magnitud del misterio que nos rodea (Guevara, 2005:104, las cursivas son mías).

Vale la pena resaltar las palabras que emplea: el misterio, la inminencia de la muerte, los ojos de la anciana, el acre olor, el sumiso pedido de disculpas, generan un ambiente de pesadumbre, de tristeza, de impotencia, de desasosiego total. El autor apela, de ese modo, a la sensibilidad del lector. Una situación de muerte inminente es la responsable de revelarle la "tragedia que encierra la vida del proletariado de todo el mundo"; esa tragedia es la que lo hermana con los demás seres humanos y busca, de igual manera, que el lector se hermane con él, con la vieja y, en un sentido abisal, con la especie humana.

El pasaje referido es sumamente trascendental en la narración del viaje, es un momento crucial del cambio entre el Ernesto Guevara que partió de Argentina y el Ernesto Guevara que siente en huesos y piel a la "Mayúscula América”. Como señala Ricardo Piglia, "El Guevara que va al camino y escribe un diario no se puede asimilar ni al turista ni al viajero en el sentido clásico. Se trata, antes que nada, de un intento de definir la identidad; el sujeto se construye en el viaje; viaja para transformarse en otro". (2005:116).

Ocurre en el Fúser, como autor y como personaje del relato, "un descubrimiento recíproco de lo realmente social dentro de lo individual y de lo realmente individual dentro de lo social" (Williams, 1988:226).

El viaje y la aventura seguirán. Ernesto y Alberto harán de polizones, de vagabundos profesionales, de descubridores, pero sus ojos verán con mayor profundidad la realidad latinoamericana en la vida de los otros, ésos a los que la vieja chilena representó en todo el dolor. Nuevamente, 
ahora tras conocer a una pareja de trabajadores en Chuquicamata, dirá: "El matrimonio aterido, en la noche del desierto acurrucados uno contra el otro, era una viva representación del proletariado de cualquier parte del mundo". Habrá, además, un nuevo elemento con el que moral y éticamente el joven Guevara se hermana con ellos: la solidaridad en el frío de la noche.

No tenían ni una mísera manta con qué taparse, de modo que le dimos una de las nuestras y en la otra nos arropamos como pudimos Alberto y yo. Fue ésa una de las veces en que he pasado más frío, pero también en la que me sentí un poco más hermano con ésta, para mí, extraña especie humana... (2005:114)

Ambos episodios son de una mayor introspección, se está cuestionando, gracias a lo desconocido, a esa "extraña especie humana", lo que él mismo es. Está anunciando, con su proceder en el viaje, una reconfiguración de sí.

Hay además un espíritu, más que de sacrificio, de verdadera solidaridad. El despojo de una de las mantas para combatir el frío se realiza en beneficio de los mineros, no es ya un sacrificio por la austeridad de la aventura sino un acto de hermandad con aquellos a quienes descubre como sus iguales. Ese episodio será fundamental para reconocerse "un poco más" hermano de la hasta entonces "extraña especie humana".

El tono de su narración en esos pasajes es mucho más crudo, menos cálido, tratando de plasmar, con toda franqueza y sin preámbulo, lo que sus ojos vieron y, asimismo, cuánto le caló en la vida el encontrarse ante una realidad ignorada, no escuchada, no vivida en carne propia.

Existe otro elemento meritorio de rescatar. Hay una toma de distancia constante al momento de narrar, el Fúser es consciente de ello: Diarios de motocicleta combina varios registros de escritura. Si bien es un diario de viaje, es al mismo tiempo una suerte de balance político de su experiencia. Es el reflejo de una sostenida reflexión sobre América Latina, "Al hacer estas notas de viaje, en el calor de mi entusiasmo primero y escritas con la frescura de lo sentido, escribí algunas extravagancias y en general creo haber estado bastante lejos de lo que un espíritu científico podría aprobar"(Guevara, 2005:127). El reparo es significativo. Dado que el viaje lo ha cambiado, que lo ha enfrentado consigo mismo antes que con nadie más, es más riguroso con sus propias impresiones. Las "extravagancias" se alejan de una búsqueda más seria, "científica", necesaria para entender a cabalidad la situación política y social de Latinoamérica. 
Perú será el próximo destino de los andantes caballeros. Ahí Guevara se maravilla con la riqueza histórica y cultural de las zonas arqueológicas, Cuzco y Machu Picchu lo asombrarán febrilmente. Con sobrada razón, Paco Ignacio Taibo II dice que "Se le enloquece el lenguaje, se le desatan las metáforas, vuelan las imágenes en sus notas de diario", también señala que "El viaje se vuelve de estudio y recopilación de datos [...]."(2007:45).

Se muestra un cambio evidente entre el inicio de la aventura y los diferentes episodios vividos. Los ojos de Guevara son los mismos, pero su mirada es más incisiva, más "científica", tratando de entender en lo más profundo su experiencia con rigor reflexivo y no solamente con "entusiasmo y frescura de lo sentido". No es ocioso insistir en el hecho de la transformación del Guevara personaje, pero de igual manera del Che autor: uno y otro son indisociables, el cambio va a la par entre lo vivido y lo escrito.

El Fúser desarrolla un fuerte sentimiento de hermandad con los menos favorecidos: la anciana enferma, los trabajadores mineros, la "grey piojosa y hedionda" de la que en un momento del viaje los quisieron separar, el indio viejo "que sacó de entre sus ropas un choclo muy apetitoso y nos lo ofreció". De ellos resalta lo mejor del ser humano, su solidaridad natural, su altivez ante las dificultades, la dignidad inquebrantable. Parece encontrar en ellos características de su personalidad; se reconoce en los más humildes, aquellos a los que la historia parece haber olvidado.

Quizá, por esa misma razón, dirá que del Cuzco hay tres miradas posibles - la del conquistador, la del criollo y la de los conquistados-, él rescata especialmente la última, la que duele a pesar de los lejanos años de la conquista:

Pero también hay un Cuzco vibrante que enseña en sus monumentos el valor formidable de los guerreros que conquistaron la región, el que se expresa en los museos y bibliotecas, en los decorados de las iglesias y en las facciones claras de los jefes blancos que aún hoy muestran el orgullo de la conquista; es el que invita a ceñir el acero y montado en caballo de lomo amplio y poderoso galope hendir la carne indefensa de la grey desnuda cuya muralla humana se debilita y desaparece bajo los cuatro cascos de la bestia. (Guevara, 2005: 150)

La indignación le corre por las letras como la rabia por sus venas. Por más "científico" que quiera ser, plasma, sin embargo, una molestia singular. Como en Ernesto, el personaje principal de Los Ríos profundos de José 
María Arguedas, hay en el joven Guevara una nostalgia y un dolor del pasado arrebatado a punta de sangre y fuego. El Fúser escribe:

Las piedras grises se han cansado de implorar la destrucción de la aborrecida raza conquistadora a sus dioses tutelares, y ahora muestran su cansancio de cosa inanimada, útil sólo para provocar la admirativa exclamación de un turista. ¿Qué puede la paciente acción de los indios que construyeron el palacio de la Inca Roca, labrando sutilmente los ángulos de la piedra, frente a la impetuosa acción del conquistador blanco que conoce el ladrillo, la bóveda y el arco de medio punto? (Guevara, 2005:153).

Sobre Machu Picchu anotará:

[...] nos encontramos aquí frente a una pura expresión de la civilización indígena más poderosa de América, inmaculada por el contacto de la civilización vencedora y plena de inmensos tesoros de evocación entre sus muros muertos de aburrimiento de no ser, y en el paisaje estupendo que lo circunda y le da el marco necesario para extasiar al soñador que vaga porque sí entre sus ruinas, o al turista norteamericano que, cargado de practicidad, encaja los exponentes de la tribu degenerada que puede ver en el viaje entre los muros otrora vivos y desconoce la distancia moral que las separa, porque son sutilezas que sólo el espíritu semiindígena de americano del sur puede apreciar (2005:159).

Además de jugar futbol en toda oportunidad, el Fúser y Alberto Granado sienten a la América Latina vibrar bajo sus pies. El Perú de César Vallejo, su majestuosidad histórica y su miseria palpable, le habla de la historia no escuchada, la que los vencidos deben narrar.

La indignación se le tatúa al ser testigo de cómo se trata a los indios "Es que para la mentalidad de la gente rica de la zona es completamente natural que el sirviente, aun yendo a pie, cargue con todo el peso y la incomodidad en un viaje de esta naturaleza" (Guevara, 2005:175). Su paso por Perú resulta fundamental en el proceso de transformación de su visión del mundo. Gracias al Dr. Hugo Pesce, conoce la poesía de Vallejo y, además, lee por primera vez a José Carlos Mariátegui. ${ }^{8}$

Al llegar a Lima hace un balance en el que aparece la revolución como palabra y necesidad “[...] Lima es la representante completa de un Perú

8 Años después, luego del triunfo guerrillero en Cuba, Guevara dedicará a Pesce uno de los ejemplares de La guerra de Guerrillas (1961). "Al Doctor Hugo Pesce, que provocara, sin saberlo quizás, un gran cambio en mi actitud frente a la vida y la sociedad, con el entusiasmo aventurero de siempre pero encaminado a fines más armoniosos con las necesidades de América". 
que no ha salido del estado feudal de la colonia: todavía espera la sangre de una verdadera revolución emancipadora." En Ucayali apunta elementos de una irreversible transformación, un enojo a una clase media de la que proviene, una molestia por la soberbia "intelectual" que ésta llega a tener $\mathrm{y}$, en cambio, una toma de partido por la gente humilde:

Nuestro carácter se aviene mucho más con el de los sencillos marineros que con los de esa pequeña clase media que, rica o no, tiene demasiado cerca el recuerdo de lo que fue para permitirse el lujo de admirar a dos viajeros indigentes. Tienen la misma crasa ignorancia que los otros, pero el pequeño triunfo que obtuvieron en la vida se les ha subido a la cabeza, y las sencillas opiniones que emiten van respaldadas por la enorme garantía que supone el ser lanzadas por ellos. (Guevara, 2005:193)

El 14 de junio de 1952, cumpliendo 24 años, señala la fecha de manera sarcástica como "El día de San Guevara". Llevan cerca de tres semanas en el leprosario de San Pablo. Desea pasar su cumpleaños entre los leprosos. El Fúser es ya el Che del futuro próximo, al menos así lo sugieren las palabras que pronuncia en el brindis por un aniversario más de su nacimiento:

Quiero recalcar algo más un poco al margen del tema de este brindis: aunque lo exiguo de nuestras personalidades nos impide ser voceros de su causa, creemos, y después de este viaje más firmemente que antes, que la división de América en nacionalidades inciertas e ilusorias es completamente ficticia. Constituimos una sola raza mestiza que desde México hasta el estrecho de Magallanes presenta notables similitudes etnográficas. Por eso, tratando de quitarme toda carga de provincialismo exiguo, brindo por Perú y por la América Unida. (Guevara, 2005:196)

De su discurso resalta de inmediato la idea de "la América Unida". Latinoamérica es una sola en sus dificultades, una sola también en el futuro: la "Mayúscula América" está contenida en sus letras, en sus balances, en las metáforas que la describen. Resulta significativo cómo, en los distintos momentos del viaje, sus preocupaciones mutan. Aunque éstas se encuentran marcadas por "hacer camino al andar", como dicen los versos de Antonio Machado, la evolución en ellas pasa por la idea del descubrimiento de Latinoamérica a la preocupación por el otro, y de ahí a la necesidad de entender América como una sola, lejos de todo provincianismo. Con el viaje, con el paso del Fúser al Che, nace también su latinoamericanismo y el acendrado antiimperialismo que lo caracterizara. 
El viaje, en estricto sentido, concluye ahí en el Perú. La Mambo Tango, una balsa así bautizada en honor al (des)oído musical del Che, será la que los transporte, por haberse quedado dormidos en plena navegación, con dirección a Brasil, obligándolos a cruzar en canoa hacia Leticia, en Colombia. Allí se convierten en fugaces estrellas de futbol. El Fúser presume de sus dotes de portero, "me atajé un penal que va quedar para la historia de Leticia", y Alberto Granado es bautizado como "Pedernerita" en honor al legendario jugador argentino. En Bogotá conocerán a Alfredo Di Stéfano, que les da dos pases de entrada al partido entre Real Madrid y Millonarios.

Venezuela será su último destino, ahí Alberto consigue un empleo de manera rápida. Es la despedida entre los dos. El Che regresará a la Argentina para concluir con los estudios de medicina, pero en su diario hay una "Acotación al margen". Él mismo siente su transformación, el viaje lo hizo otro, un otro que:

[...] en el momento en que el gran espíritu rector dé el tajo enorme que divida toda la humanidad en solo dos fracciones antagónicas, estaré con el pueblo, y sé porque lo veo impreso en la noche que yo, el ecléctico disector de doctrinas y psicoanalista de dogmas, aullando como poseído, asaltaré las barricadas o trincheras, teñiré en sangre mi arma y, loco de furia, degollaré a cuanto vencido caiga en mis manos [...]. Ya siento mis narices dilatadas, saboreando el acre olor de pólvora y de sangre, de muerte enemiga; ya crispo mi cuerpo, listo a la pelea y preparo mi ser como un sagrado recinto para que en él resuene con vibraciones nuevas y nuevas el aullido bestial del proletariado triunfante. (Guevara, 2005: 208, las cursivas son mías)

El Fúser sabe que ha nacido el guerrero, el futuro guerrillero. Hay en esa declaración una necesidad de dejar en claro cómo y para qué estará con el pueblo. El tono de la confesión, además de febril, es reflejo de su metamorfosis y de la urgencia de acción. No deja de sorprender, sin embargo, -o quizá por eso-, que lo encendido de sus letras no pierdan el toque poético. Su cuerpo se transforma en recinto de las vibraciones de lo nuevo, su futuro está escrito en la noche. Si antes había escrito que su sino era viajar, en lo enfebrecido de su declaración anuncia el trillo de la lucha armada que emprenderá años después.

Diarios de motocicleta es, en suma, un texto fundacional del quehacer literario del Che. A decir de Fernando Diego García y Oscar Sola, "Todos sus hallazgos de escritura estarán estrechamente ligados con el viaje, es decir con el registro de la distancia" (1997:28). Pero no se trata solamente 
el registro del viaje, como si fuese una bitácora con anotaciones minuciosas, sino la forma que adopta al registrarlo. Si bien por el cambio en sus preocupaciones desea dar cuenta de los más mínimos detalles para él interesantes, la forma de la narración, el trabajo literario, es el hilo conductor. Además de lo que muestra a los ojos de los lectores, Diarios de motocicleta vale en lo que de voluntad artística contiene.

\section{LA SEMILLA NARRATIVA}

Con Diarios de motocicleta se revela una manera propia de narrar. Hay, en primera instancia, un método que el Che empleará para escribir otras narraciones, especialmente en los Pasajes de la guerra revolucionaria. Existen notas iniciales, apenas registros de sus impresiones, que serán posteriormente desarrolladas, matizadas, trabajadas, con el afán de generar un efecto de acercamiento en el lector.

En relatos futuros empleará el mismo modo de trabajo. Pasajes de la guerra revolucionaria parte de la experiencia personal queriendo transformarla en una colectiva; no es simplemente el relato de lo que sus ojos vieron, es la experiencia guerrillera del Ejército Rebelde vivida en sus letras. Otro aspecto no menos importante recae en el examen constante de lo registrado.

El Che se convierte así en el primer lector y crítico de sus letras. Si en Diarios de motocicleta califica algunos pasajes de "extravagancias" en sus notas primigenias, en el diario de guerra del Congo dirá:

Esta es la historia de un fracaso. Desciende al detalle anecdótico, como corresponde a episodios de la guerra, pero está matizada de observaciones $y$ de espíritu crítico ya que estimo que, si alguna importancia pudiera tener el relato, es la de permitir extraer experiencias que sirvan para otros movimientos revolucionarios (Guevara, 2009; 27).

Se trata pues de una recuperación de la experiencia vivida; es una rememoración reelaborada lo que brinda a sus lectores. Además, la advertencia al lector será un elemento continuo, inaugurado en Diarios de Motocicleta, pero que recorre La guerra de guerrillas, Pasajes de la guerra revolucionaria, y su diario del Congo. Todos estos textos tienen la característica común de ser concebidos para tener lectores, ése es su objetivo. Solamente El diario del Che en Bolivia y Otra vez, el diario escrito en su segundo viaje por tierras latinoamericanas, salen de ese patrón: el primero 
por el desenlace de su vida, en el segundo porque la inminencia de la lucha guerrillera y el desarrollo de la Revolución cubana le impiden la posterior valoración.

En sus advertencias al lector establece un pacto de lectura o, al menos, una sugerencia de cómo leer lo que ha escrito. En la "Advertencia preliminar" del diario en el Congo señala:

Estas notas serán publicadas transcurrido bastante tiempo desde su dictado y, tal vez, el autor no pueda ya hacerse responsable de lo que aquí está dicho. El tiempo habrá limado muchas aristas y, si tiene alguna importancia su aparición, los editores podrán hacer las correcciones que crean necesarias, mediante las pertinentes llamadas, a fin de aclarar los acontecimientos o las opiniones a la luz del tiempo decantado (Guevara, 2009: ídem).

Otro elemento a destacar es el poder descriptivo de su narración, como bien anota Alejandro González Acosta:

En sus numerosos pasajes literarios, el Che destaca por un rasgo eminente entre todos: su poder descriptor. Se constata desde el primer instante la aguda facilidad que posee para captar, procesar y elaborar las semblanzas de personajes, en un caso, y en otros, las representaciones de lugares, situaciones y ambientes, [...] (González, 1990:56, las cursivas son mías).

Diarios de motocicleta muestra la que a la larga será una marca inconfundible en el Che: su narración se basa en la descripción de situaciones o eventos a partir de la observación de los personajes. A decir de Denia García Ronda:

Si hay algo que sintetiza el método testimonial del Che es precisamente su visión del hombre. [...] hay una atención especial a las actitudes y hechos de los combatientes y de los campesinos de las zonas alzadas [...] El Che es, como Gómez y Martí, un cronista del hombre en situación de guerra, más que un escribiente de esa situación (García, 2013)

Aunque la observación de la analista cubana se refiere a los Pasajes de la guerra revolucionaria, este rasgo se presenta desde Diarios de motocicleta. Basta con mencionar cómo describe la situación de los mineros chilenos o el episodio de la anciana enferma.

En Diarios de motocicleta está la simiente de un estilo propio que a lo largo de los diarios, las cartas e incluso los ensayos se percibe: descripciones certeras y breves, muy poca solemnidad, chispazos de humor, sarcasmo e ironía, así como un lenguaje poético. 
El "poeta frustrado" que fue Guevara jamás se consideró escritor en el sentido profesional del término, pero el Che es también lo que sus letras dicen.

El Che es él y su literatura leída, escrita, y, a fin de cuentas, vivida. Así, ese viaje a la semilla, plasmado en Diarios de motocicleta, fue, en estricto sentido, un viaje al origen del futuro guerrillero. Por ello, en el Che siempre asoma el Fúser y su espíritu aventurero que, con la literatura, hizo un viaje tanto o más importante que el de 1952: el de las letras.

\section{BIBLIOGRAFÍA}

BAJTÍN, M. (1982); Estética de la creación verbal. México: Siglo XXI.

FOUCAULT, M. (1996); De lenguaje y literatura. Barcelona: Instituto de Ciencias de la Educación de la Universidad Autónoma de Barcelona / Paidós.

GARCÍA FERNANDO, D., y O. Sola (1997); CHE. Sueño rebelde. México: Diana.

GARCÍA MÁRQUEZ, G., y M. Vargas Llosa (1988); Diálogo sobre la novela latinoamericana. Lima: Perú Andino.

GARCÍA RONDA, D. (2013); "El escritor Che: sin darle pluma por pistola”. http:// elsudamericano.wordpress.com/2013/05/14/el-escritor-che-sin-darle-pluma-por-pistola/

GONZÁLEZ ACOSTA, A. (1990); Che escritor. Estudio introductorio. Guadalajara: Xalli / Universidad de Guadalajara.

GUEVARA, E. (1977); Escritos y discursos, t. 9, La Habana: Editorial de Ciencias Sociales. , (2005); Diarios de Motocicleta, notas de un viaje por América Latina. Buenos Aires: Planeta. , (2009); Pasajes de la guerra revolucionaria (Congo). México: Ocean Sur.

LLANES, J. M. (2010); Che entre la literatura y la vida (notas para el corazón y la memoria). La Habana: Instituto Cubano de Investigación Cultural Juan Marinello.

OGARRIO, G. (2009); “Che Guevara: una política de la transfiguración”, en La jornada semanal, 745. www.jornada.unam.mx (14 de junio de 2009).

PIGLIA, R. (2005); “Ernesto Guevara, rastros de lectura”, en El último lector. Barcelona: Anagrama.

PIMENTEL, L. A. (2012); Constelaciones I. Ensayos de teoría narrativa y literatura comparada. México: Bonilla Artigas Editores / UnAM.

TAIBO II, P. I. (2007); Ernesto Guevara también conocido como el Che. México: Planeta.

VITTIER, C. (2005); “Introducción”, en Ernesto Guevara, Diarios de Motocicleta, notas de un viaje por América Latina. Buenos Aires: Planeta. 